\title{
Anti-GAD-associated limbic encephalitis: an unusual clinical manifestation from northwest of Ireland
}

\author{
Salman Mansoor ${ }^{*}$ (D) and Kevin Murphy
}

\begin{abstract}
We report an unusual manifestation of anti-GAD-associated limbic encephalitis in a 59-year-old man following pacemaker insertion for cardiac pauses. Clinically, the association of anti-GAD antibody with limbic encephalitis is rare. He presented with a complex constellation of symptoms, posing a diagnostic and therapeutic challenge.
\end{abstract}

Keywords: Anti-GAD antibody, Limbic encephalitis, Dysautonomia, Seizures, Autoimmune encephalitis

\section{Introduction}

Autoimmune encephalitis is a distinct group of disorders which are characterized by specific antibodies. The clinical manifestation of these disorders encompasses seizures, cognitive problems and psychiatric symptoms [1]. Autoimmune encephalitis is associated with neoplastic and non-neoplastic conditions [2]. Anti-glutamic acid decarboxylase (GAD) antibodies have two distinct isoforms, GAD65 and GAD67 [3]. The two sites where these antibodies are expressed are GABAergic neurons and islet cells [4]. The neurological conditions that are caused by GAD antibodies are stiff-person syndrome, cerebellar ataxia and rarely limbic encephalitis $[5,6]$.

\section{Case}

We report a case of a 59-year-old Irish gentleman who presented initially with a transient loss of consciousness while sitting on a dinner table. His family described days leading to this, he was experiencing "dizzy spells" described as light-headedness. He was brought to a regional hospital where his cardiac workup on telemetry revealed two cardiac pauses. An MRI brain was done to rule out any acute vascular event, and this was unremarkable Fig. 1.

He was shifted to coronary care unit where he had a prolonged cardiac pause requiring cardiopulmonary resuscitation for less than a minute. Two days later, a decision was made to put in a pacemaker, he was shifted to another cardiac referral centre and a pacemaker was implanted

\footnotetext{
* Correspondence: salmanmansoor.dr@gmail.com

Department of Neurology, Sligo University Hospital, Sligo, Ireland
}

uneventfully. He was shifted back to the regional hospital, and owing to his stable condition and no further cardiac pauses, he was discharged home.

His past medical history included anxiety, depression, prostate cancer for which he had brachytherapy 9 years ago, vitrectomy (left eye), peptic ulcer disease, hiatal hernia, Barrett's oesophagus, osteoporosis, vitiligo and rosacea.

He had seen psychiatry for his depression and anxiety and was on mirtazapine for 11 years which he stopped taking of his own accord 1 year earlier. He was a nonsmoker and drinks alcohol socially.

The day after his discharge, he felt left-sided numbness and a transient difficulty in his speech for which he was readmitted, and he underwent several investigations during the next 6 days including a pacemaker interrogation, cardiac echo and a CT brain which were normal.

A psychiatrist was consulted who was of the opinion that his symptoms may be due to health-related anxiety and laid down a plan for community counselling and he was discharged.

He presented to the emergency department 9 days later with symptoms of tiredness and dizziness since the last 3 days; a routine workup including blood tests was normal so he was discharged.

Five days later, he again presented to the hospital with a new set of symptoms, this time with some confusion, memory issues and anxiety. He would ask the same question repeatedly and would have problems remembering short-term memory, e.g. "who came last night to meet him". His family reported these symptoms to be 


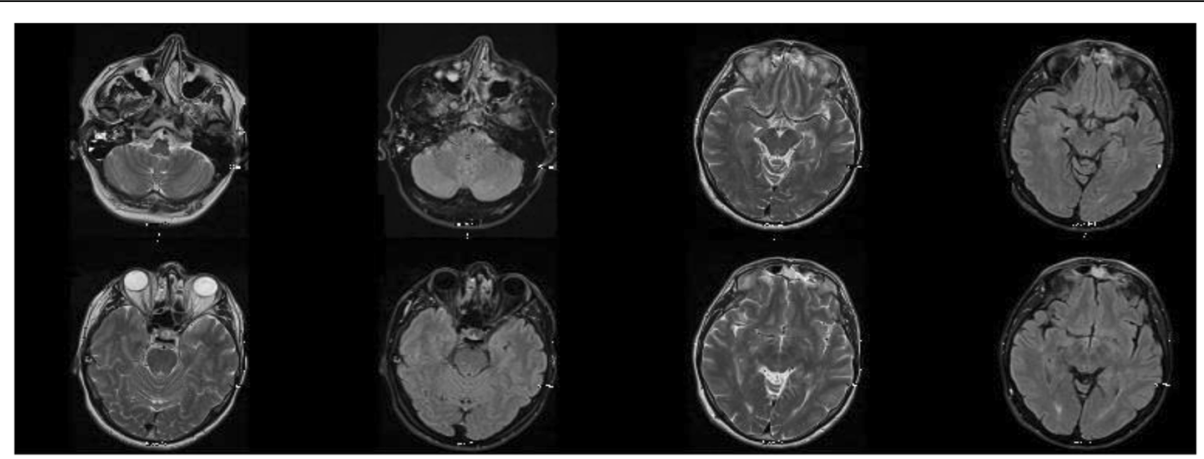

Fig. 1 Pre-pacemaker MRI brain showed chronic microvascular ischaemic changes around periventricular areas; however, there are no abnormal lesions in the temporal lobes

fairly acute in the last 3 weeks which were never experienced before. His neurological exam was normal; however, there was a tendency to preservation. Cerebrospinal fluid (CSF) analysis was done which showed no white cells, a mildly elevated protein of $0.56 \mathrm{~g} / \mathrm{L}$. Aspirin and mirtazapine were also started. MRI brain to rule out an acute stroke and an EEG to look for any epileptic activity were both advised.

Three days prior to his investigations, his family described quivering around his lips lasting a few seconds under a minute without any loss of awareness that occurred a couple of times. He was also noted to be shaky while holding the television remote for 1-2 min the night prior to his investigations. The morning of his investigations, he was noted to have a blank stare with right eye twitching.

Both MRI brain and EEG were performed within a week. MRI brain post-pacemaker is shown in Fig. 2. The EEG showed intermittent slowing in the right temporal region while during hyperventilation, there was rhythmic $4 \mathrm{~Hz}$ right temporal slowing lasting $20 \mathrm{~s}$.

He was started on intravenous acyclovir (IV) $10 \mathrm{mg} / \mathrm{kg}$ every $8 \mathrm{~h}$, IV methylprednisolone $1 \mathrm{~g}$ once daily for 5 days, IV immunoglobulin $0.4 \mathrm{~g} / \mathrm{kg} / \mathrm{day}$ for 5 days and levetiracetam $250 \mathrm{mg}$ twice daily which was titrated up to $750 \mathrm{mg}$ twice daily in the next 2 weeks.

At this point, another CSF analysis was repeated that showed 8-10 WCC, $80 \%$ lymphocytes with a protein of 0.6. Further tests were requested on his CSF including viral PCRs, TB PCR, TB culture and sensitivity, cryptococcal antigen, fungal culture, cytology, flow cytometry, anti-NMDA and anti-GAD.

Serum samples were checked for anti-NMDA, antiGABA-B, anti-GAD, anti-AMPA 1, anti-AMPA 2, antiVGKC, anti-Lgi1, anti-Casp2, anti-thyroid, anti-TPO, anti-Hu, anti-Yo and anti-DPPX. He was further also checked for Sjogren's antibodies, serum protein electrophoresis, complement levels, ANA/ENA profiles, HIV, Lyme disease and syphilis serology. A CT thorax, abdomen and pelvis were also done.

Serum anti-GAD and CSF anti-GAD were positive with 2000 units $/ \mathrm{mL}$ and 1892 units/mL, respectively (reference range, $0-5$ units $/ \mathrm{mL}$ ). The rest of the test results were normal.

Based on which a diagnosis of anti-GAD-associated limbic encephalitis was made.

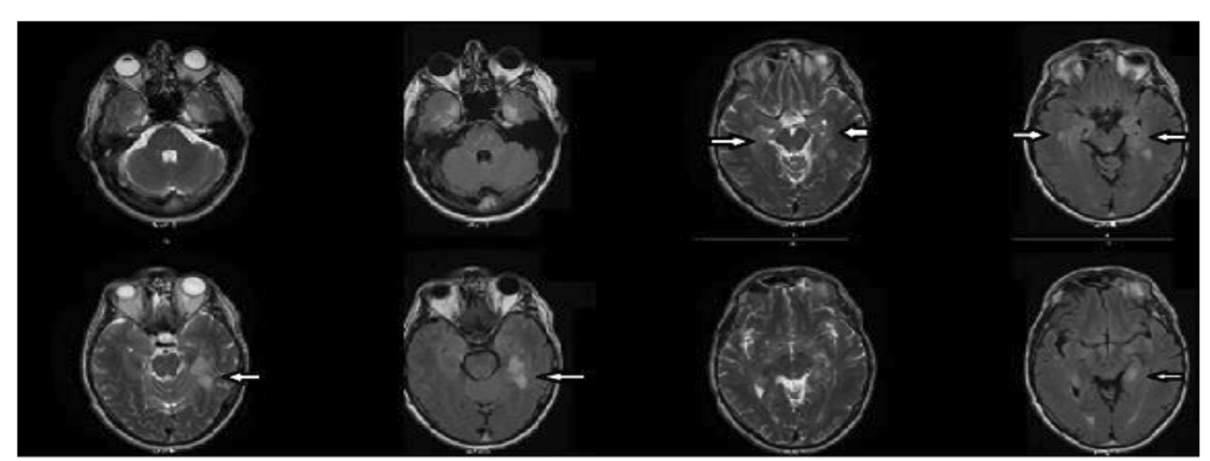

Fig. 2 Post-pacemaker MRI brain 1 month after showing extensive T2 hyper-intensities and signal changes in bilateral hippocampi, anterior subtemporal regions as two small areas in the left mesial temporal regions. There was a mild degree of swelling in these areas without any restricted diffusion and no contrast enhancement 


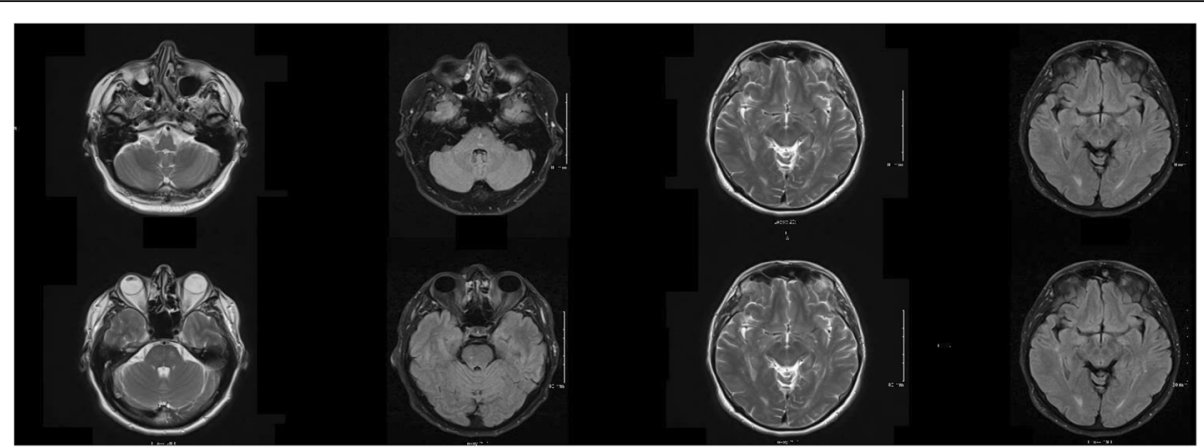

Fig. 3 A follow-up MRI brain done 3 months afterwards showing interval resolution of previously documented temporal lobe signal alteration, likely representing limbic encephalitis

\section{Later course}

He completed his IV methylprednisolone and IV immunoglobulin for 5 days, his HSV-PCR was negative and IV acyclovir was stopped after 6 days. He switched to oral prednisolone $60 \mathrm{mg}$ OD which was tapered every 2 weeks. He had a second course of IV immunoglobulin after 3 weeks. He had issues with his cognition at times repeating things. He started improving slowly and was discharged after staying in the hospital for a month.

\section{Follow-up}

He was recently readmitted 3 months after his discharge for a further workup including an interval MRI brain scan and CSF analysis including anti-GAD antibodies. His recent MRI brain scan is shown in Fig. 3. CSF analysis showed no pleocytosis, a mildly raised protein of $0.55 \mathrm{~g} / \mathrm{L}(0.15-0.45 \mathrm{~g} /$ $\mathrm{L})$, and anti-GAD antibody levels were reduced to 137 units $/ \mathrm{mL}$ in CSF and 1760 units/mL in serum.

Clinically, he self-reported a reduced recall of written information. He was managing his activities of daily living at home comfortably. However, he did not return back to driving. His cognitive testing with Addenbrooke's Cognitive Examination (ACE-iii) was completed on which he scored 76/100. He is currently on prednisolone, levetiracetam, mirtazapine, aspirin and vitamin B6.

\section{Discussion}

A review article published in 2016 reported 58 published cases with 37 in adults and 21 in paediatric age group of anti-GAD-associated encephalitis. Autoimmune conditions including diabetes, psoriasis, common variable immune deficiency, celiac disease and autoimmune thyroiditis were co-reported in $48 \%$ of cases [7]. Neoplastic conditions including small cell lung carcinoma and malignant thymoma were reported in $10 \%$ of the cases [7]. In our case, a history of vitiligo and treated past prostate cancer may be of clinical relevance.
Anti-GAD-associated encephalitis as previously reported can clinically manifest with seizures (97\%), cognitive impairment (66\%), psychiatric symptoms (28\%), fever (14\%), dysautonomia (12\%), cerebellar features (7\%) and headaches (5\%) [7]. In our patient, seizures, cognitive problems and psychiatric symptoms were the hallmarks. Preceding these features, cardiac block and syncope could have been secondary to dysautonomia as described. Severe dysautonomia related to anti-GAD-related limbic encephalitis was also reported to be the cause of death in a 9year-old child that developed after immunotherapy [8]. However, our patient had the pacemaker at the start of his illness which could have been associated with a positive outcome.

MRI brain and EEG abnormalities have been described in $78 \%$ and $77 \%$ cases, respectively. These were both abnormal in our patient [7]. Positive antibodies both in serum and CSF have been reported in $60 \%$ of the cases which was consistent in our case [7].

The management of anti-GAD-associated limbic encephalitis consists of immunotherapy with steroids, IV immunoglobulin and plasma exchange with variable response $[7,9]$. The long-term prognosis varies in individual cases.

In our case, a follow-up at 4 months did show marked improvement in clinical imaging features, patient's symptoms and a reduction in CSF of anti-GAD antibody levels.

\section{Conclusion}

The onset of limbic encephalitis in our case is unusual, and the initial symptoms with syncope followed by pacemaker insertion could be incidental or did they play a role in precipitating this form of encephalitis remains unknown. Clinically, the association of anti-GAD antibody with limbic encephalitis is rare. The unusual manifestation of anti-GAD antibody posed both a diagnostic and therapeutic challenge in our case, with a positive outcome at 4 months. 


\section{Acknowledgements}

Not applicable

\section{Financial relationships}

All authors have declared that they have no financial relationships at present or within the previous 3 years with any organizations that might have an interest in the submitted work

\section{Other relationships}

All authors have declared that there are no other relationships or activities that could appear to have influenced the submitted work.

\section{Authors' contributions}

SM and KM were involved in writing the manuscript and diagnosing and treating the patient. Both authors read and approved the final manuscript.

\section{Ethics approval and consent to participate}

The patient was informed and written consent was taken from the patient for this publication. Animal subjects: all authors have confirmed that this study did not involve animal subjects or tissue.

\section{Competing interests}

The authors declare that they have no competing interests.

Received: 12 December 2019 Accepted: 3 February 2020

Published online: 13 February 2020

\section{References}

1. Dalmau J, Rosenfeld MR. Paraneoplastic syndromes of the CNS. Lancet Neurol. 2008;7(4):327-40.

2. Lancaster E, Dalmau J. Neuronal autoantigens--pathogenesis, associated disorders and antibody testing. Nat Rev Neurol. 2012;8:380-90.

3. Lernmark A. Glutamic acid decarboxylase--gene to antigen to disease. J Intern Med. 1996;240(5):259-77.

4. Scherbaum WA. Cytoplasmic islet cell antibodies (ICA): towards a molecular understanding of the autoantigens. Clin Endocrinol. 1994;40(1):15-8.

5. Seissler J, Bieg S, Yassin N, Mauch L, Northemann W, Boehm BO. Association between antibodies to the MR 67,000 isoform of glutamate decarboxylase (GAD) and type 1 (insulin-dependent) diabetes mellitus with coexisting autoimmune polyendocrine syndrome type II. Autoimmunity. 1994;19(4):231-8.

6. Honnorat J, Saiz A, Giometto B, Vincent A, Brieva L, de Andres C, et al. Cerebellar ataxia with anti-glutamic acid decarboxylase antibodies: study of 14 patients. Arch Neurol. 2001;58(2):225-30.

7. Gagnon MM, Savard M. Limbic encephalitis associated with GAD65 antibodies: brief review of the relevant literature. Can J Neurol Sci. 2016 Jul; 43(4):486-93.

8. Ben Achour N, Ben Younes T, Rebai I, Ben Ahmed M, Kraoua I, Ben Y-TI. Severe dysautonomia as a main feature of anti-GAD encephalitis: report of a paediatric case and literature review. Eur J Paediatr Neurol. 2018;22(3):548-51.

9. Malter MP, Helmstaedter $\mathrm{C}$, Urbach $\mathrm{H}$, et al. Antibodies to glutamic acid decarboxylase define a form of limbic encephalitis. Ann Neurol. 2010; 67(4):470-8.

\section{Publisher's Note}

Springer Nature remains neutral with regard to jurisdictional claims in published maps and institutional affiliations.

\section{Submit your manuscript to a SpringerOpen ${ }^{\circ}$ journal and benefit from:}

- Convenient online submission

Rigorous peer review

- Open access: articles freely available online

High visibility within the field

- Retaining the copyright to your article

Submit your next manuscript at $\boldsymbol{\nabla}$ springeropen.com 